\title{
Development of a 1D thermofluid code for divertor target plate modeling
}

\author{
Z.J. Jackson ${ }^{\mathrm{a}}$, J.R. Nicholas ${ }^{\mathrm{a}}$, P.T. Ireland ${ }^{\mathrm{a}}$
}

${ }^{a}$ Oxford Thermofluids Institute, Department of Engineering Science, University of Oxford, Osney Mead Industrial Estate, Oxfordshire, OX2 OES, United Kingdom

\begin{abstract}
The Oxford Divertor Thermo-Fluid Code (OxDTFC) is a numerical model to assess and compare the steady state thermo-fluid performance of the cooling systems present in the divertor target plate region of a fusion tokamak. Two water-cooled divertor target plate concepts have been used to demonstrate the model: an ITER-like monoblock system and the High Pressure Jet Cascade (HPJC) modular concept. Model validation was carried out by comparing results for the ITER-like monoblock system with experimental and numerical data in the literature. This comparison showed OxDTFC could accurately replicate divertor target plate thermo-fluid results across various coolant flow rates, incident heat fluxes, and geometric parameters. OxDTFC is used to compare the performance of the ITER-like monoblock and HPJC systems under equivalent thermal boundary conditions. This analysis shows the HPJC system has pumping power requirements of $\sim 65 \%$ and coolant flow rates of $\sim 50 \%$ less than a comparable ITER-like monoblock system.
\end{abstract}

Keywords:

ITER, DEMO, divertor, monoblock, HPJC

\section{Nomenclature}

$A$ - PFC area $\left[\mathrm{m}^{2}\right]$

$c_{p}$ - Specific heat at constant pressure $[\mathrm{J} / \mathrm{kg} \cdot \mathrm{K}]$

$D$ - Diameter $[\mathrm{m}]$

$G$ - Mass flux $\left[\mathrm{kg} / \mathrm{m}^{2} \cdot \mathrm{s}\right]$

$h$ - Heat transfer coefficient $\left[\mathrm{W} / \mathrm{m}^{2} \cdot \mathrm{K}\right]$

$i$ - Enthalpy $[\mathrm{J} / \mathrm{kg}]$

$k$ - Thermal conductivity $[\mathrm{W} / \mathrm{m} \cdot \mathrm{K}]$

$\dot{m}$ - Mass flow rate $[\mathrm{kg} / \mathrm{s}]$

$P$ - Pressure $[\mathrm{Pa}]$

$\dot{P}$ - Pumping power $[\mathrm{W}]$

$\dot{q}$ - Heat flux $\left[\mathrm{W} / \mathrm{m}^{2}\right]$

$Q$ - Heat input $[\mathrm{W}]$

$s$ - HPJC hexagonal side length [m]

$t$ - Thickness [m]

$T$ - Temperature $[\mathrm{C}]$

$\mathrm{w}$ - Toroidal width $[\mathrm{m}]$

$x$ - Coolant quality

$Y$ - Swirl tape twist ratio

$\mathrm{z}$ - Poloidal length [m]

\section{Greek Letters}

$\delta t$ - Swirl tape thickness [m]

$\rho$ - Density $\left[\mathrm{kg} / \mathrm{m}^{3}\right]$

$\mu$ - Dynamic viscocity $[\mathrm{kg} / \mathrm{m} \cdot \mathrm{s}]$

$\sigma$ - Surface tension $[\mathrm{N} / \mathrm{m}]$

\section{Nondimensional Numbers}

Email address: zachary.jackson@eng.ox.ac.uk (Z.J. Jackson)
$\mathrm{Eu}$ - Euler Number $=\frac{\Delta P}{\rho U^{2}}$

Ja - Jakob Number $=\frac{\rho_{l}}{\rho_{g}} \frac{c_{p}\left(T_{s a t}-T\right)}{H_{f g}}$

Pr - Prantl Number $=\frac{\mathcal{C}_{p} \mu}{k}$

Re - Reynolds Number $=\frac{G D}{\mu}$

\section{Subscripts}

$b$ - Bulk coolant

$c$ - Critical

$g$ - Gas phase

$h$ - Hydraulic

$f g$ - Heat of vapourisation

$h s$ - Heat sink

i - Inlet, inner

$j$ - Jet

$l$ - Liquid phase

NCB - Nucleate boiling

o - Outlet, outer

ONB - Onset of nucleate boiling

sat - Saturated

SP - Single phase

TP - Two phase

$w$ - Channel wall

\section{Introduction}

The divertor has a number of key functions: setting the plasma boundary, enabling the formation of a highconfinement mode (H-mode) plasma, maintaining plasma purity via removal of reaction byproducts (helium ash), 
and shielding the outer walls from thermal loads [1, 2]. The heat extracted in the divertor can also contribute to the total power generation of the fusion reactor.

Located at the base of the vacuum chamber of the ITER and DEMO tokamaks, a divertor cassette is composed of various regions. An ITER-like cassette, with central dome and inner/outer target plate regions (IVT/OVT), is shown in Figure 1. The IVT and OVT are subject to the highest incident heat fluxes (IHFs) within the tokamak. For ITER and DEMO, these are predicted to be 10 - $20 \mathrm{MW} / \mathrm{m}^{2}$ during slow transients and $5-10 \mathrm{MW} / \mathrm{m}^{2}$ at steady state [3]. These high peak heat fluxes present during steady state operation necessitate an active cooling approach and, in combination with the effects of neutron irradiation, present several component design challenges $[4,5]$.



Figure 1: A 3D model of an ITER-like divertor cassette [6].

To manage the thermal loads associated with the ITER divertor, the monoblock design, with its associated structural components shown in Figure 2, has been developed. However, there are difficulties directly applying this design to DEMO due to the longer plasma burn times associated with the operation of a fully functional power station [7]. Therefore, new approaches of cooling the divertor target plates are likely needed. Several concepts have been investigated and developed. This includes various helium cooled modules [8, 9] as well as the High Pressure Jet Cascade (HPJC) heat sink design, shown in Figure 3, developed by the University of Oxford [10].

This paper focuses on developing a numerical model to allow for a high level comparison between multiple divertor cooling systems. Specifically, OxDTFC outputs performance results for a cooling system composed of a single, uncurved strip of a vertical target plate exposed to surface thermal boundary conditions and operating at a steady state. A key feature of the model is the rapid manipulation of cooling system geometric parameters, hydraulic conditions, and thermal boundary conditions. This allows for multiple high level comparisons of small system varia-

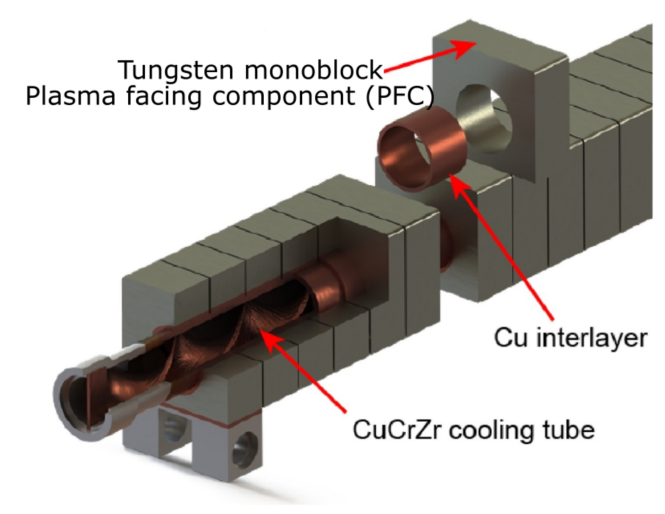

Figure 2: A typical ITER-like monoblock, showing tungsten tile shielding and internal $\mathrm{CuCrZr}$ cooling channel (with inserted swirl tape) [11].

tions to be quickly and easily accomplished.

The reference point for the cooling system comparisons undertaken by OxDTFC is set by the performance results of an ITER-like monoblock, currently the baseline design for a DEMO divertor $[12,13]$. The following thermohydraulic parameters are the comparison metrics used to distinguish between system performance:

- Coolant mass flow rates;

- System pressure drops;

- System pumping power;

- Coolant temperature changes.

Incident heat fluxes and subsequent heat sink temperatures set the boundary conditions of any cooling system and directly influence these key parameters.

\section{OxDTFC development}

\subsection{Overview}

OxDTFC is a one-dimensional rapid simulation tool that produces results which should be viewed as an approximation or an input to a more accurate conjugate heat transfer (CHT) analysis. It is not an all-encompassing numerical model - the functional range of the code is limited to expected operational conditions of the cooling systems considered. This means post-critical heat flux flow conditions, and corresponding "burnout" type analyses, are not accurately modeled.

OxDTFC is a modular system where further blocks of code, representing different cooling systems, can be added and analyzed as desired. Code representing the behaviour of an ITER-like monoblock and a HPJC-1a module are two such modular numerical models developed in this paper. Within the larger activities of the EUROfusion work 

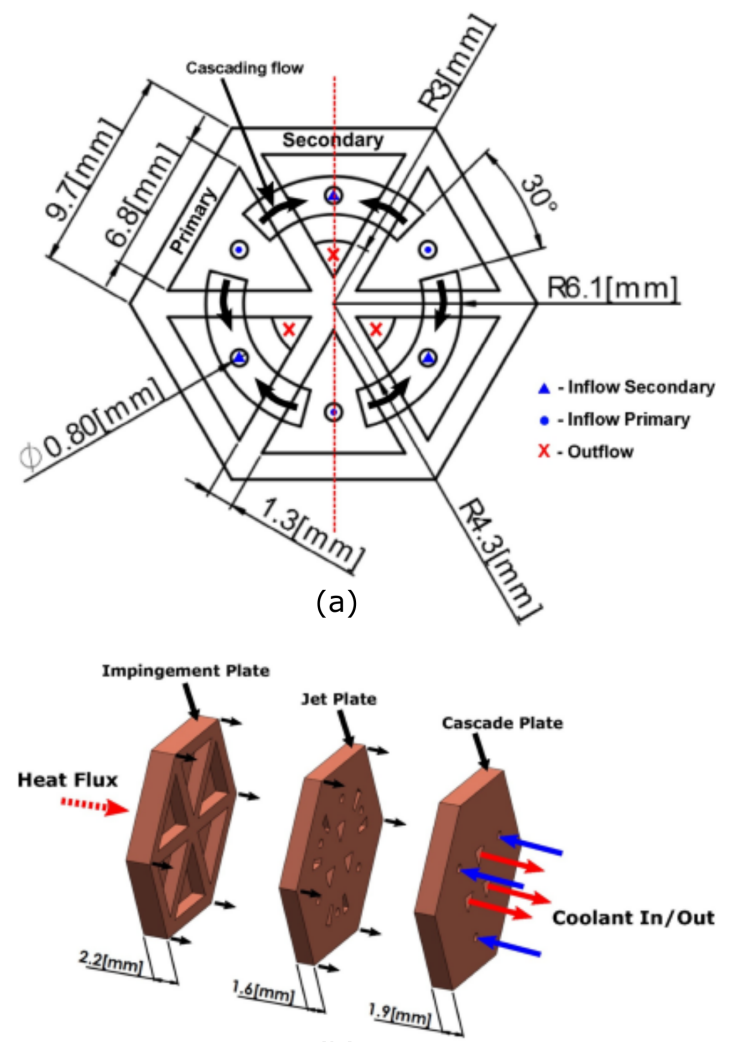

(b)

Figure 3: The HPJC-1a module, showing coolant flow paths within the internal geometry (a) and an exploded view of the stacked plates (b) $[10]$.

package 'divertor', the results provided by the code may be valuable inputs to efforts involving $2 \mathrm{D}$ and $3 \mathrm{D}$ modelling approaches focused on furthering the plasma facing component (PFC) heat sink and cooling circuit thermohydraulic design. This includes efforts reported in $[7,10$, 14, 15, 16, 17], among others.

\subsection{Calculation method}

The vertical target plate is subdivided into several discrete poloidal segments of fixed length. The exact length of each segment is dependent on the cooling system being analysed. In the ITER-like monoblock case, this length corresponds to $\sim 0.01 \%$ of the total poloidal length of the target plate. This allows for any expected local variations in surface heat flux $\dot{q}$ to be accurately accounted for, whilst not creating an excessively large computational requirement. A visual representation of the ITER-like monoblock computational section is shown in Figure 4 with characteristic lengths, temperatures, and IHFs noted.

The calculations of the thermo-hydraulic parameters are completed for each segment via an iterative process based on the bulk properties of the coolant. Convergence is assumed achieved when there is less than a $1 \%$ difference in calculated value between iterative steps. The characteristic heat sink temperatures are calculated via a similar iterative scheme dependent on the heat transfer coefficient

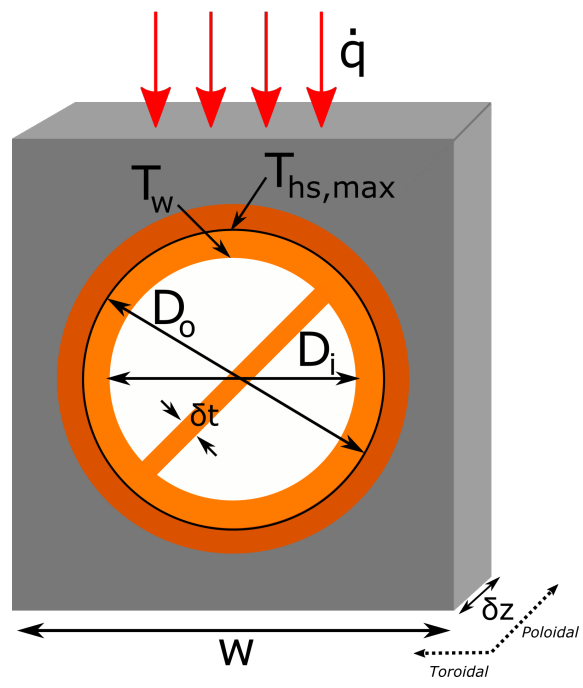

Figure 4: The ITER-like monoblock structure as modeled in OxDTFC. The swirl tape (with thickness $\delta \mathrm{t}$ ) can be excluded to simulate a smooth channel.

present in the section. A flow chart describing the numerical processes for the ITER-like monoblock is shown in the Appendix in Figure A.17.

To maintain consistency with the ITER-like monoblock and HPJC-1a designs, water is used as the coolant. Liquid and vapour properties from $0.1 \mathrm{MPa}$ to 22.06 $\mathrm{MPa}$ (the critical pressure of water) are taken from the $\mathrm{Na}$ tional Institute of Standards and Technology (NIST) fluids database [18]. These are compiled into a table, where a two-dimensional interpolation yields fluid properties at a given input temperature and pressure. The copper alloy Copper-Chromium-Zirconium ( $\mathrm{CuCrZr}$ ) is used as the heat sink material, pure copper used as the interlayer material, and tungsten as the PFC shield. Their properties are taken from Appendix A of the ITER Structural Design Criteria for In-vessel Components (SDC-IC) [19]. A simple one-dimensional interpolation determines the relevant metal properties at a given temperature.

\subsubsection{Heat input}

The segment heat input $Q$ is calculated via the multiplication of the characteristic PFC tile width $\mathrm{w}$ and an integration of the heat flux profile $\dot{q}(z)$, assumed constant in the toroidal direction, along the poloidal segment length $\delta \mathrm{z}$ :

$$
Q=\mathrm{w} \cdot \int_{z_{i}}^{z_{i}+\delta z} \dot{q}(z) d z
$$

where $z_{i}$ and $z_{i+1}$ are the local poloidal coordinates of the calculation step.

The average heat flux $\bar{q}$ incident on the section is given by an integration of the local heat flux profile divided by $\delta z$ as: 


$$
\bar{q}=\frac{1}{\delta z} \cdot \int_{z_{i}}^{z_{i}+\delta z} \dot{q}(z) d z
$$

\subsubsection{Coolant temperature}

The segment output temperature $T_{o}$ is calculated according to the First Law of Thermodynamics for bulk coolant at temperatures less than the local saturation temperature $T_{\text {sat }}$ :

$$
T_{o}=T_{i}+\frac{Q}{\dot{m} c_{p, l}}
$$

where $\dot{m}$ is the coolant mass flow rate and $c_{p, l}$ is the specific heat of the coolant. For analyses of the ITER-like monoblock, $T_{o}$ of one segment is set as the input temperature, $T_{i}$, of the next. If the bulk coolant temperature reaches $T_{\text {sat }}$ it is assumed to remain there for the remaining sections of the analysis.

\subsubsection{Heat sink temperature}

For the ITER-like monoblock, the maximum heat sink temperature $T_{h s, \max }$ is located where the heat sink meets the interlayer material between the coolant channel and the PFC tile, as shown in Figure 4. For a system operating at steady state, convective flux is equal to conductive flux [20] via:

$$
f_{\text {peak }} \cdot \bar{q}=h\left(T_{w}-T_{l}\right)=\frac{t_{h s}}{k_{h s}}\left(T_{h s, \max }-T_{w}\right)
$$

Thus:

$$
T_{h s, \max }=T_{w}+f_{p e a k} \cdot \bar{q} \cdot\left(\frac{t_{h s}}{k_{h s}}\right)
$$

where $T_{w}$ is the temperature at the coolant interface, $t_{h s}$ is the difference between the inner and outer diameter of the coolant channel, and $k_{h s}$ is the temperature-dependent thermal conductivity of the heat sink material. The modifying factor $f_{\text {peak }}$ is included to modify the wall heat flux apparent on the cylindrical surface of the coolant channel from the incident heat flux on the flat PFC tiles. This value is expected to be between $1.3-2[21,22,23,24]$. The value of $T_{w}$ is determined via the heat transfer coefficient of the segment, defined in Section 2.2.4.

\subsubsection{Heat transfer coefficients}

The heat transfer mechanisms present in each segment of the ITER-like monoblock are dependent on the flow conditions present within the coolant channel. The single and two-phase heat transfer coefficients are calculated via the correlations in the following subsections.

\subsubsection{Single-phase forced convection}

The Dittus-Boelter correlation [25], with the Seider-Tate correction [26], yields the single-phase heat transfer coefficient $h_{S P}$ for turbulent flow (Reynolds number Re $\geq$ $10,000)$ and is defined as:

$$
h_{S P}=\frac{k_{l}}{D_{e}} \cdot 0.023 \operatorname{Re}^{0.8} \operatorname{Pr}^{0.4}\left(\frac{\mu_{b}}{\mu_{w}}\right)^{0.14}
$$

where $\operatorname{Pr}$ is the Prantl number of the segment and the equivalent heat diameter $D_{e}$ is set to the diameter of the coolant channel. The coolant thermal conductivity $k_{l}$ is defined according to the bulk temperature of the segment. The Seider-Tate correction increases calculation accuracy where there are meaningful temperature differences between the bulk flow and the heat transfer surface, likely at high heat fluxes, via a ratio of coolant viscosities. Thus, the bulk and near-wall region viscocities, $\mu_{b}$ and $\mu_{w}$, respectively, are calculated according to the coolant conditions in these regions.

In the case where a swirl tape insert is present, the Reynolds number uses the hydraulic diameter $D_{h}$ (defined in Section 2.2.5) as the characteristic length, and $D_{e}$ is modified to equal:

$$
D_{e}=\frac{\pi D_{i}^{2}-4 \delta t D_{i}}{\pi D_{i}+2\left(D_{i}-\delta t\right)}
$$

where $D_{i}$ is the inner diameter of the coolant channel and $\delta t$ is the thickness of the swirl tape. Additionally, the value of $h_{S P}$ is modified by a factor, developed by Gambill [27], dependent on the twist ratio $Y$ to yield:

$$
h_{S P}^{*}=h_{S P} \cdot 2.18 Y^{-0.09}
$$

\subsubsection{Subcooled boiling}

While the bulk temperature of the segment is less than $T_{\text {sat }}$, boiling will occur locally along the wall surface when $T_{w}$ exceeds the onset temperature of nucleate boiling, $T_{O N B}$ :

$$
T_{\mathrm{ONB}}=T_{\text {sat }}+\Delta T_{\mathrm{ONB}}
$$

where $\Delta T_{\text {ONB }}$ is given by the Bergles and Rohsenow correlation [28]:

$$
\Delta T_{\mathrm{ONB}}=0.556\left(\frac{\bar{q}}{1082 P_{b}^{1.156}}\right)^{0.463 P_{b}^{0.0234}}
$$

where $P_{b}$ is the bulk pressure of the coolant in the segment.

The overall heat flux is assumed to be a combination of nucleate boiling and single-phase forced convection components, $\dot{q}_{N B}$ and $\dot{q}_{S P}$. This is given by a correlation developed by Chen [29]:

$$
\bar{q}=\dot{q}_{N B}(\mathrm{~S})+\dot{q}_{S P}(\mathrm{~F})
$$

where $\mathrm{S}$ is the nucleate boiling suppression factor and $\mathrm{F}$ is the convective boiling enhancement factor. In the subcooled boiling regime voidage is assumed small and ignored as purely a wall effect with no impact on the bulk coolant, therefore the value of $\mathrm{F}$ is set to $1[30]$. The value of $\mathrm{S}$ is defined according to [31]: 


$$
\mathrm{S}= \begin{cases}{\left[1+0.12\left(\operatorname{Re}_{T P}\right)^{1.14}\right]^{-1}} & \operatorname{Re}_{T P}<32.5 \\ {\left[1+0.42\left(\operatorname{Re}_{T P}\right)^{0.78}\right]} & 32.5 \leq \operatorname{Re}_{T P} \leq 70\end{cases}
$$

$\operatorname{Re}_{T P}$ is an effective two-phase Reynolds number, defined via:

$$
\operatorname{Re}_{T P}=\operatorname{Re}_{l} \mathrm{~F}^{1.25} \times 10^{-4}
$$

where $\mathrm{Re}_{l}$ is equal to the Reynolds number of the bulk flow.

Thus, expanding Equation 11 for the subcooled boiling region:

$$
\bar{q}=h_{\mathrm{NCB}}\left(T_{w}-T_{\mathrm{sat}}\right)(S)+h_{\mathrm{SP}},\left(T_{w}-T_{b}\right)
$$

where $T_{b}$ is the temperature of the bulk coolant and $h_{\mathrm{SP}}$, is defined using a standard Dittus-Boetler correlation. The two-phase, nucleate boiling component heat transfer coefficient $h_{\mathrm{NCB}}$ is given by the Forster-Zuber correlation [28]:

$$
h_{\mathrm{NCB}}=0.00122\left(\frac{k_{l}^{0.79} c_{p, l}^{0.45} \rho_{l}^{0.49}}{\sigma^{0.5} \mu_{l}^{0.29} i_{f g}^{0.24} \rho_{v}^{0.24}}\right) \Delta T_{s a t}^{0.25} \Delta P_{s a t}^{0.75}
$$

where $\rho_{l}, \mu_{l}$ and $\sigma$ are the density, viscosity, and surface tension, respectively, of the liquid coolant (taken at bulk properties) and $i_{f g}$ is the enthalpy of vaporization of the segment, while $\rho_{v}$ is the vapor density of the coolant. $\Delta T_{\text {sat }}$ is the local wall superheat $T_{w}-T_{\text {sat }}$ and $\Delta P_{\text {sat }}$ is difference between bulk and saturation pressures of the section $P_{\text {sat }}\left(T_{w}\right)-P_{\text {sat }}\left(T_{s}\right)$.

\subsubsection{Two-phase forced convection}

The onset of fully developed boiling requires taking into account the vapor fraction, or quality, $x$, of the coolant. The value of $x$ is calculated using the enthalpy $i$ of the coolant in the segment via:

$$
x=\frac{i-i_{f}}{i_{f g}}
$$

where $i_{f}$ is the enthalpy of liquid coolant. This assumes thermodynamic equilibrium and perfect coolant mixing throughout the channel [28].

The calculation of the wall temperature in this flow regime utilizes the Chen superposition given in Equation 11. In this regime, the single phase component, $\dot{q}_{\mathrm{SP}}$, is the function of a modified Dittus-Boelter relationship:

$$
q_{\mathrm{SP}}=\frac{k_{l}}{D_{e}} \cdot 0.023\left[\frac{G(1-x) D_{h}}{\mu_{l}}\right]^{0.8} \operatorname{Pr}_{l}^{0.4}(\mathrm{~F})
$$

where $G$ is the mass flux of the segment and $\mathrm{F}$ is defined according to [28]:

$$
\mathrm{F}= \begin{cases}1 & \frac{1}{X_{t t}} \leq 0.1 \\ 2.35\left(\frac{1}{X_{t t}}+0.213\right)^{0.736} & \frac{1}{X_{t t}}>0.1\end{cases}
$$

with the Lockhart-Martinelli parameter $X_{t t}$ given by:

$$
X_{t t}=\left(\frac{1-x}{x}\right)^{0.9}\left(\frac{\rho_{v}}{\rho_{l}}\right)^{0.5}\left(\frac{\mu_{l}}{\mu_{v}}\right)^{0.1}
$$

and $\mu_{v}$ is the viscosity of coolant vapor.

The two phase component is the same as in Equation 14, with $h_{\mathrm{NCB}}$ given by Equation 15 and $S$ calculated via Equation 12.

\subsubsection{Pressure drop}

Hydraulic losses in the ITER-like monoblock cooling system are the sum of frictional and, when two-phase flows are present, associated vapour loss components. As frictional losses dominate the overall losses, the associated vapour generation losses are not considered.

Losses are calculated via a friction factor $f$. For smooth channels, this value is defined using the Blasius correlation:

$$
f=0.079 \mathrm{Re}^{-0.25}
$$

For channels with a swirl tape insert this value is modified by a factor developed by Lopina and Bergles [32] as:

$$
f_{\text {swirl }}=f \cdot 2.75 Y^{-0.406}
$$

The swirl tape necessitates the use of the hydraulic diameter as the characteristic length. This is given by:

$$
D_{h}=\frac{\pi D_{i}^{2}-4 \delta t D_{i}}{\pi D_{i}-2 \delta t}
$$

The pressure drop in the section is thus defined as:

$$
\Delta P=2 \cdot f \frac{G^{2}}{\rho} \frac{\delta z}{D_{h}}
$$

where $\rho$ is the density of the bulk coolant in the segment.

\subsubsection{Pumping power}

The pumping power required for each segment is calculated via:

$$
\dot{P}=\frac{\dot{m} \cdot \Delta P}{\rho}
$$

where $\Delta P$ is the value given by Equation 23 . The total pumping power requirements of the cooling scheme are calculated as the sum of the pumping powers for each individual segment along the poloidal length.

\subsubsection{Critical heat flux (ITER-like monoblock only)}

A modification of the TONG-75 correlation recommended by Baxi [21] yields the wall critical heat flux $\dot{q}_{\mathrm{CHF}}$ of an ITER-like monoblock divertor regime as: 
$\dot{q}_{\mathrm{CHF}}=0.23 \cdot f_{\mathrm{ref}} C_{f} G i_{f g}\left(1+0.00216 \cdot\left(\frac{P_{b}}{P_{c}}\right)^{1.8} \mathrm{Re}^{0.5} \mathrm{Ja}\right)$

where $P_{b}$ and $P_{c}$ are the bulk and critical pressures of the coolant, respectively, Ja is the Jakob number, and $f_{\text {ref }}$ is given by:

$$
f_{\text {ref }}=8 \operatorname{Re}^{-0.6}\left(\frac{D_{h}}{0.0127}\right)^{0.32}
$$

The modifying factor $C_{f}$ is dependent on the twist ratio of the inserted swirl tape and is defined as:

$$
C_{f}=1+\frac{0.87}{Y^{0.4}}
$$

and the value of incident critical heat flux (ICHF) is given by:

$$
\dot{q}_{\mathrm{ICHF}}=\frac{\dot{q}_{\mathrm{CHF}}}{f_{\text {peak }}}
$$

\section{OxDTFC validation}

The thermal performance of OxDTFC has been validated against experiments undertaken by Boyd et al [33], for ITER-like monoblocks with smooth channels, and Marshall et al $[34,35]$ for mock-ups with and without swirl tapes.

The hydraulic performance of OxDTFC has been validated against experimental data gathered by General Atomics [21] and CEA Cadarache at the Le Cruesot electron beam facility [36].

The Boyd, Marshall and CEA Cadarache experiments are for a single channel monoblock mock-up, similar in structure to Figure 4. The Baxi experiment used a dualchannel monoblock structure. OxDTFC exploits the symmetry of this setup about the mid-plane, thereby calculating results for a single channel.

\subsection{Monoblock temperatures}

The channel wall temperatures predicted by OxDTFC, and measured in the Boyd experiments, are shown in Figure 5 . The setup is defined by the following parameters:

- Heated length: $200 \mathrm{~mm}$;

- Monoblock width: $30 \mathrm{~mm}$;

- Channel inner diameter: $10 \mathrm{~mm}$;

- Coolant inlet temperature: $20^{\circ} \mathrm{C}$;

- Coolant inlet pressure: $0.21 \mathrm{MPa}$;

- Coolant mass flux: $1200 \mathrm{~kg} / \mathrm{m}^{2} \cdot \mathrm{s}$.
Very good agreement is found between the data sets at all four axial locations. The wall temperatures are accurately predicted in the heat flux regions where the coolant remains single-phase, from 0 to approximately 0.8 $\mathrm{MW} / \mathrm{m}^{2}$. The transition from single-phase to two-phase heat transfer mechanisms, at an incident heat flux of around $0.8 \mathrm{MW} / \mathrm{m}^{2}$ and denoted by the change in wall temperature gradient, is also accurately predicted. OxDTFC also provides good agreement in the two-phase flow regimes for heat fluxes above $0.8 \mathrm{MW} / \mathrm{m}^{2}$, where the maximum and average errors of $\sim 11 \%$ and $\sim 4 \%$, respectively, can be attributed to the uncertainties contained within the twophase heat transfer correlations used.

The monoblock temperatures predicted by OxDTFC, and measured in the Marshall experiments, are shown in Figures 6 and 7 . The setup is defined by the following parameters:

- Heated length: $40 \mathrm{~mm}$ (smooth); $30 \mathrm{~mm}$ (swirl);

- Monoblock width: $15.7 \mathrm{~mm}$;

- Channel inner diameter: $7.7 \mathrm{~mm}$ (smooth); $7.3 \mathrm{~mm}$ (swirl);

- Swirl tape thickness: $1 \mathrm{~mm}$;

- Swirl tape twist ratio: 2 ;

- Coolant inlet temperature: $70^{\circ} \mathrm{C}$;

- Coolant inlet pressure: $1 \mathrm{MPa}$;

- Coolant velocity: $1 \mathrm{~m} / \mathrm{s}$.

Very good agreement is found between OxDTFC and the smooth channel mock-up data (Figure 6) in the singlephase and two-phase flow regions at incident heat fluxes between 0 and $4 \mathrm{MW} / \mathrm{m}^{2}$. The predicted and measure values begin to diverge past this region until CHF operation begins, around $7 \mathrm{MW} / \mathrm{m}^{2}$, with OxDTFC underestimating the mock-up temperature. In this heat flux region, local film boiling develops along the heated side of the coolant channel. This serves to increase the measured temperature relative to what would be expected if the system were at thermodynamic equilibrium, as OxDTFC assumes. Once CHF operating conditions are reached OxDTFC becomes inaccurate as it does not model this flow regime - the predicted line gives what would be expected if twophase forced convective heat transfer mechanisms were still present.

Excellent agreement is found between OxDTFC and the swirl tape mock-up (Figure 7) for the single and twophase forced convective regions for heat fluxes between 0 and $12 \mathrm{MW} / \mathrm{m}^{2}$. Accuracy is retained throughout the twophase region due to the effects of the swirl tape, which inhibits the development of local film boiling by forcing coolant mixing. As expected, predicted temperatures are inaccurate in the post-CHF flow regime, located at heat fluxes greater than $12 \mathrm{MW} / \mathrm{m}^{2}$. 


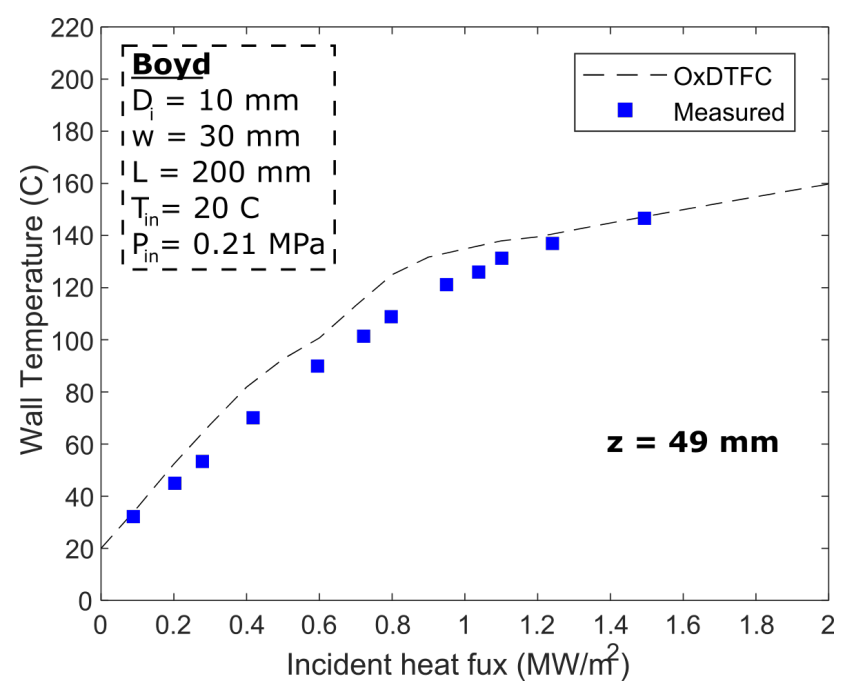

(a)

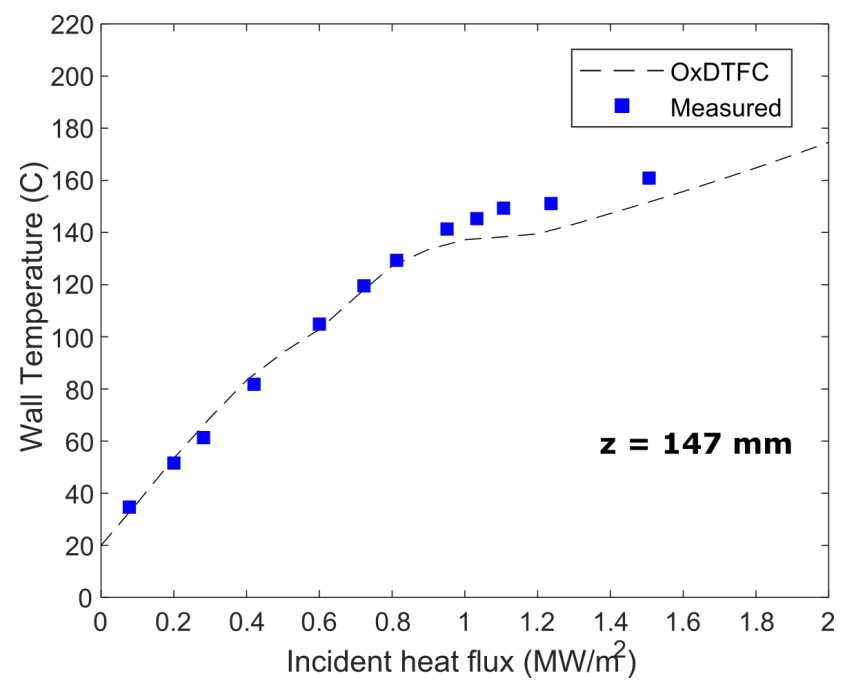

(c)

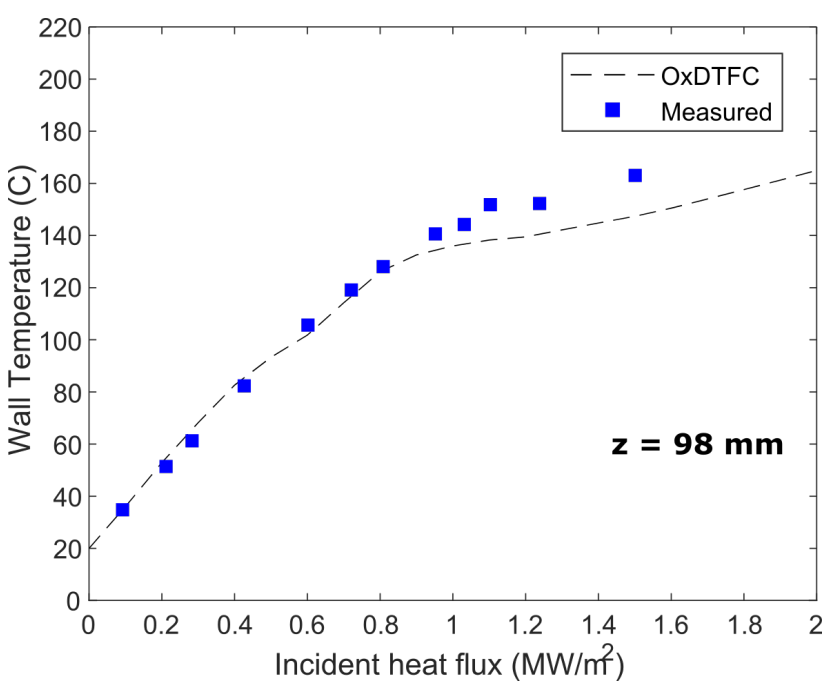

(b)

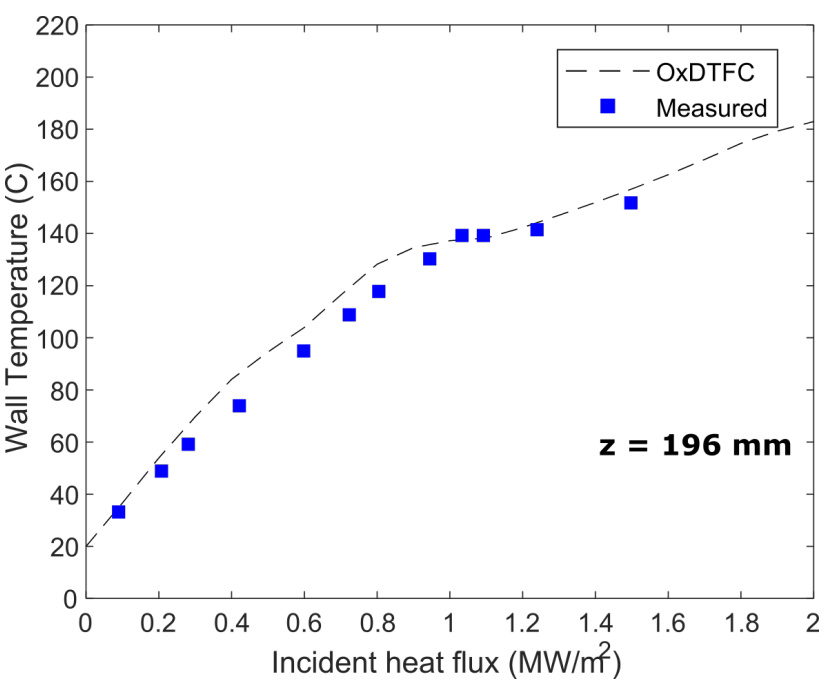

(d)

Figure 5: OxDTFC predicted and measured values of channel wall temperature for a smooth channel at incident heat fluxes from 0 to 2 $\mathrm{MW} / \mathrm{m}^{2}$ at axial locations of $49 \mathrm{~mm}(\mathrm{a}), 98 \mathrm{~mm}$ (b), $147 \mathrm{~mm}$ (c), and $196 \mathrm{~mm}$ (d) of the total $200 \mathrm{~mm}$ mock-up length.

\subsection{Pressure drop and pumping power}

The system pressure drop comparisons between OxDTFC and the CEA Cadarache experiments are shown in Figure 8, for thin swirl tapes, and in Figure 9, for thick swirl tapes. The setup is defined by the following parameters:

- Total power input: $200 \mathrm{~kW}$;

- Heated length: $100 \mathrm{~mm}$ uniform; $200 \mathrm{~mm}$ peaked heat flux length;

- Monoblock width: $23 \mathrm{~mm}$;

- Channel inner diameter: $10 \mathrm{~mm}$;

- Swirl tape thicknesses: $0.8 \mathrm{~mm}$ (thin) and $2 \mathrm{~mm}$ (thick);

- $100^{\circ} \mathrm{C}$ coolant subcooling at exit;
- Coolant inlet pressure: 3.5 MPa.

The pressure drop for a thin swirl tape is slightly underestimated, with a maximum discrepancy of $\sim 8 \%$ occurring at the highest flow rates. OxDTFC also slightly overestimates the pressure drop for thick swirl tapes, where the maximum error of $\sim 6 \%$ also occurs at the highest flow rates. Overall, there is excellent agreement between both sets of results.

Figure 10 shows the comparison between OxDTFC predicted, and Baxi measured, pumping powers at the following experimental parameters:

- Incident heat flux: $2 \mathrm{MW} / \mathrm{m}^{2}$;

- Heated length: $1.2 \mathrm{~m}$;

- Monoblock width: $40 \mathrm{~mm}$; 


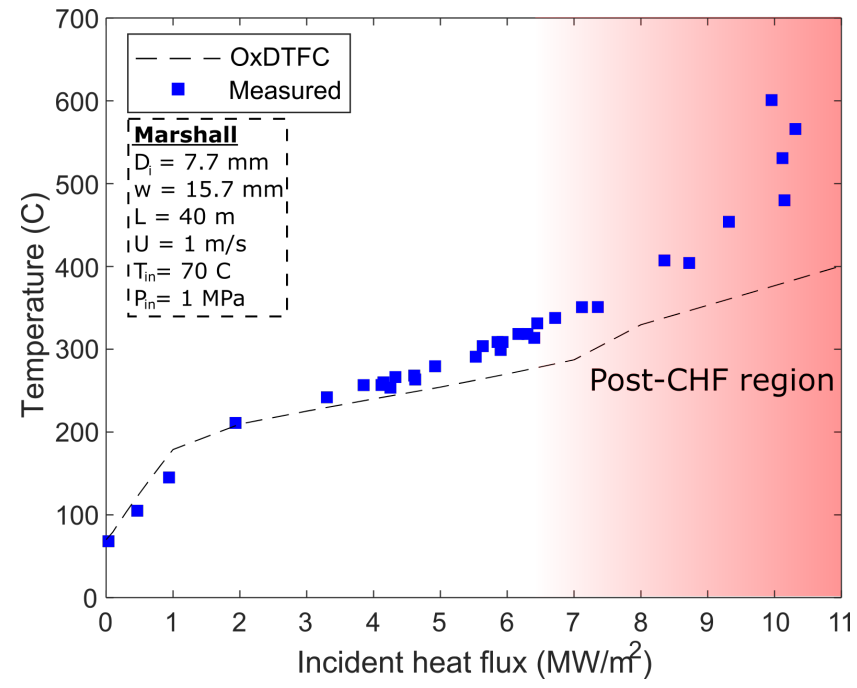

Figure 6: OxDTFC predicted and measured monoblock mock-up temperatures for a smooth channel at incident heat fluxes from 0 to $11 \mathrm{MW} / \mathrm{m}^{2}$, with the post-CHF region indicated.

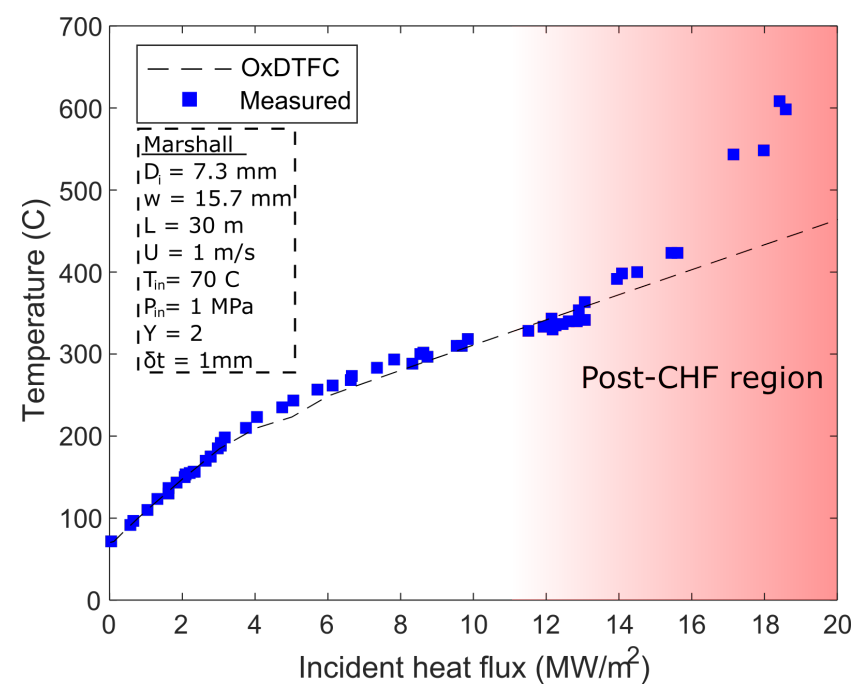

Figure 7: OxDTFC predicted and measured monoblock mock-up temperatures for a channel with an inserted swirl tape $(Y=2, \delta \mathrm{t}$ $=1 \mathrm{~mm}$ ) at incident heat fluxes from 0 to $20 \mathrm{MW} / \mathrm{m}^{2}$, with the post-CHF region indicated.

- Channel diameter: $10 \mathrm{~mm}$;

- Swirl tape thickness: $0.8 \mathrm{~mm}$;

- Swirl tape ratio: 2;

- Coolant inlet temperature: $150^{\circ} \mathrm{C}$;

- Coolant inlet pressure: $4 \mathrm{MPa}$.

The results show excellent agreement with the measured experimental data. The same $\sim 8 \%$ discrepancy is present as in the comparison with the CEA Cadarache data for a similarly thin swirl tape at the same twist ratio.

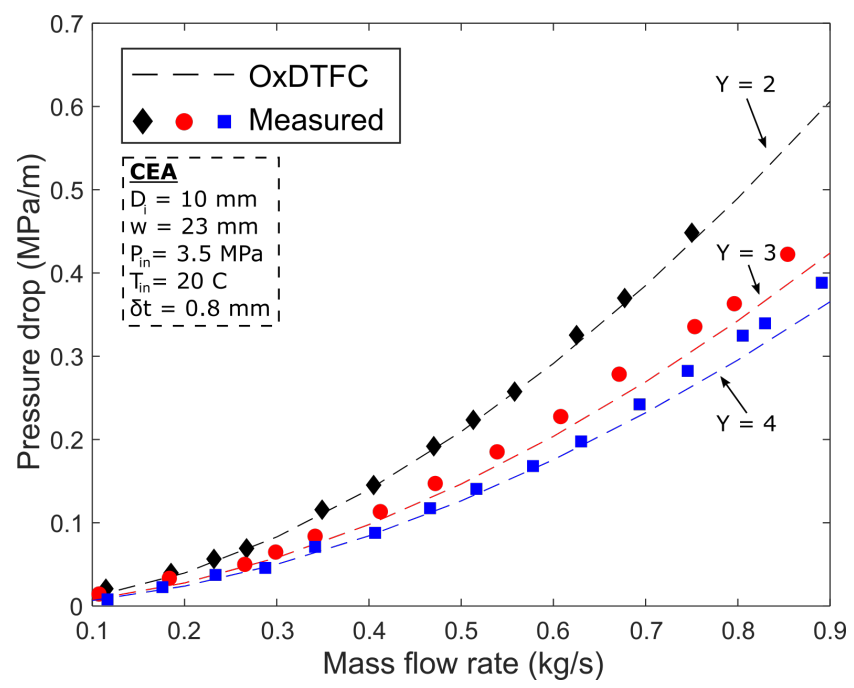

Figure 8: OxDTFC predicted and measured pressure drop results at a constant heat input for a thin swirl tape $(\delta \mathrm{t}=0.8 \mathrm{~mm})$ at varied twist ratios and coolant mass flow rates from 0.1 to $0.9 \mathrm{~kg} / \mathrm{s}$.

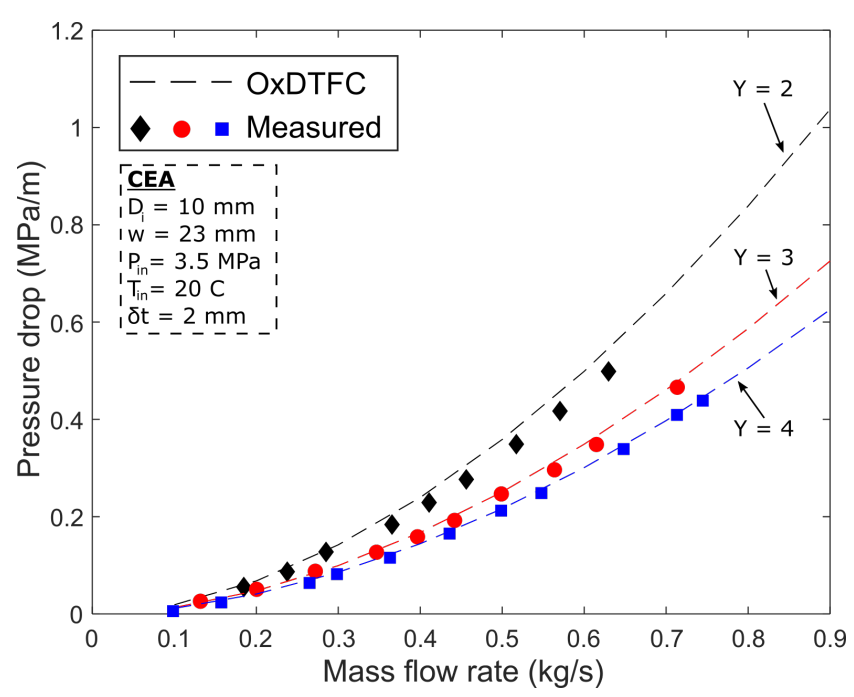

Figure 9: OxDTFC predicted and measured pressure drop results at a constant heat input for a thick swirl tape $(\delta \mathrm{t}=2 \mathrm{~mm})$ at varied twist ratios and coolant mass flow rates from 0.1 to $0.9 \mathrm{~kg} / \mathrm{s}$.

\section{HPJC-1a module calculation method}

A theoretical poloidal strip of HPJC-1a modules is arrayed in a flat-to-flat arrangement, as shown in Figure 11. Thus, when calculating the power input to each individual module via Equation 1 the segment length $\delta$ z corresponds to the poloidal height of the HPJC-1a hexagon, given by:

$$
\delta \mathrm{z}=\sqrt{3} s
$$

where $s$ is the side length of the module $(9.7 \mathrm{~mm})$. Similarly, to account for the hexagonal nature of the HPJC-1a module, the width parameter w used in Equation 1 is modified to:

$$
\mathrm{w}^{*}=\frac{3}{2} s
$$




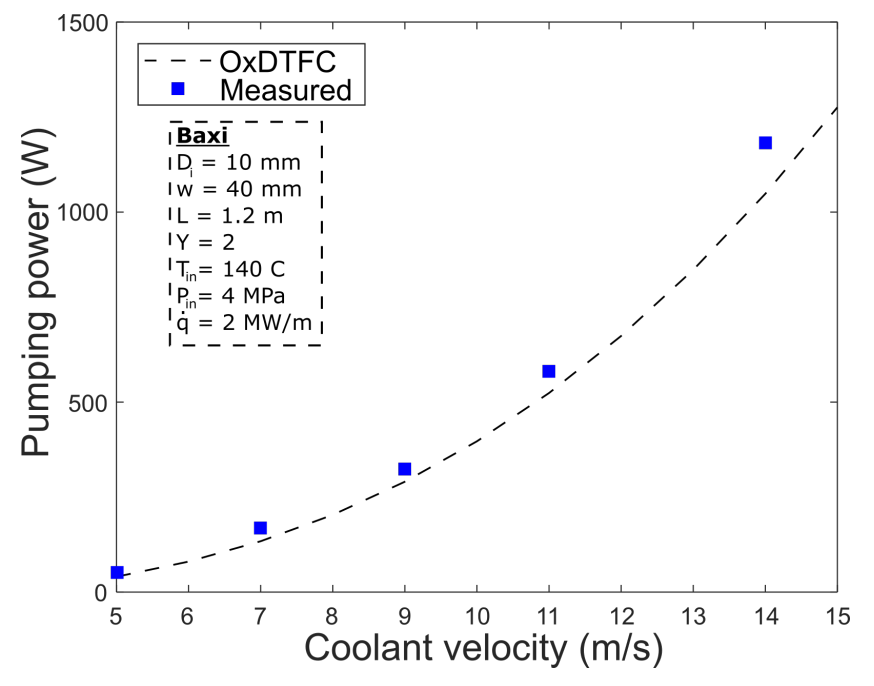

Figure 10: OxDTFC predicted and measured pumping power results at a constant incident heat flux $\left(q=2 \mathrm{MW} / \mathrm{m}^{2}\right)$ over a range of coolant velocities from $5-15 \mathrm{~m} / \mathrm{s}$.

thereby ensuring the power input to the module is correct - using the maximum toroidal width of the module would result in an incident power level higher than actually experienced by each module. The average heat flux to each module $\bar{q}$ is calculated via Equation 2. A visual representation of this computational segment is shown in Figure 12.

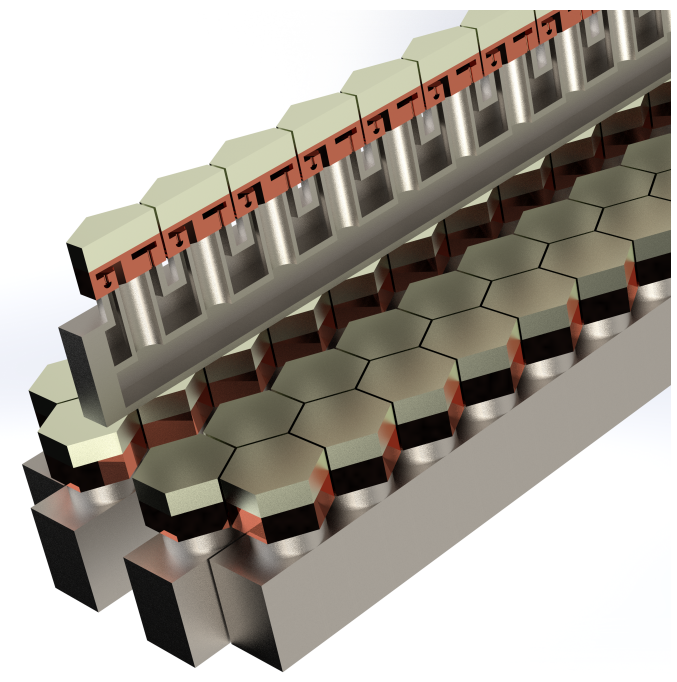

Figure 11: An example section of an OVT composed of several discrete arrays of HPJC-1a modules mounted on a theoretical manifold system.

The peak temperature and pressure drop of the HPJC1a module are calculated using results from computational fluid dynamics (CFD) simulations of the module that have been experimentally validated [10]. Key calculations set jet velocity and diameter, $U_{j}$ and $D_{j}$, respectively, as the characteristic values. $U_{j}$ is calculated via:

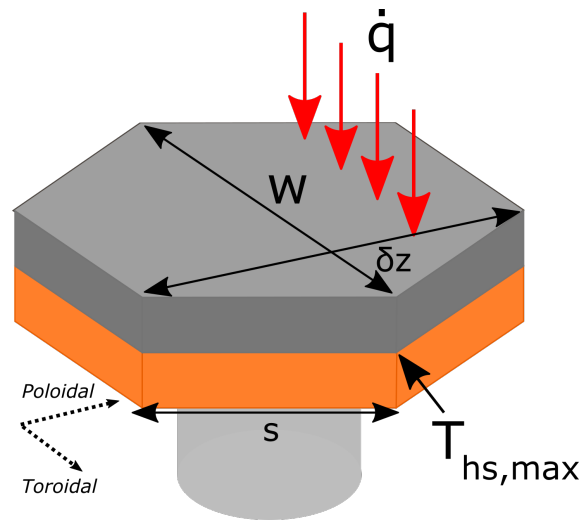

Figure 12: The HPJC-1a module as modeled in OxDTFC.

$$
U_{j}=\frac{\dot{m}_{j}}{\rho \pi\left(\frac{D_{j}}{2}\right)^{2}}
$$

where $m_{j}$ is the coolant flow rate of a single jet given by:

$$
\dot{m}_{j}=\frac{\text { total module mass flow rate }}{\text { number of feed channels per module }}
$$

The data gathered by Nicholas et al in [10] is based on average IHFs applied to the module. Due to the large height $(\delta \mathrm{z})$ of the module relative to potential local variations in the heat flux, the maximum heat sink temperature is a modification of the calculated temperature value $T^{*}$, thereby accounting for the non-uniform IHF distribution along the OVT. This is done by adding a factor dependent on the peak and average heat fluxes, $\dot{q}_{\max }$ and $\bar{q}$, incident on the module:

$$
T_{h s, \max }=T^{*}+\frac{\left(\dot{q}_{\max }-\bar{q}\right) t_{h s}}{k_{h s}}
$$

where the variables take their meanings from Section 2.2. This represents a worst case scenario where the non-uniform IHF causes further peaking than already exists within the module geometry. A flow chart describing the overall calculation process is given in the Appendix in Figure A.18.

\section{Comparison of divertor cooling systems}

Using results produced by OxDTFC, the ITER-like monoblock and HPJC-1a module cooling system performances are compared in the following section.

\subsection{Target plate heat flux distribution}

The two cooling systems were compared assuming a toroidally invariant heat flux profile incident on the divertor target plate during steady-state operation. The shape of the profile is defined using parameters assumed from a DEMO1 attached plasma scenario [37] with local heat fluxes defined by: 
$\dot{q}(z)=\frac{\dot{q}_{p}}{2} \cdot e^{\left({\frac{\Sigma}{2 \lambda_{q}}}^{2}-\frac{z-z_{s}}{\lambda_{q} f_{x}}\right)} \cdot \operatorname{erf}\left(\left(\frac{\Sigma}{2 \lambda_{q}}\right)-\left(\frac{z-z_{s}}{\Sigma f_{x}}\right)\right)+\dot{q}_{B G}$

where $\dot{q}_{p}$ and $\dot{q}_{B G}$ are the peaked and background heat flux, respectively. Here, $z$ is the distance from the base of the target plate, and $z_{s}$ the location of the peak heat flux (strike point). The remaining parameters represent the plasma characteristics: the effective flux expansion $f_{x}$ is set to 5 , the power decay length $\lambda_{q}$ is set to $0.8 \mathrm{~mm}$, and the Gaussian spreading parameter $\Sigma$ set to $4.5 \mathrm{~mm}$ $[38,37]$.

The total power input to the divertor is approximated to be $259 \mathrm{MW}$, with $112 \mathrm{MW}$ deposited on the target plates [12]. The largest portion - $46.7 \%$ - is incident on the OVT [12], which will be the area of focus for the comparison.

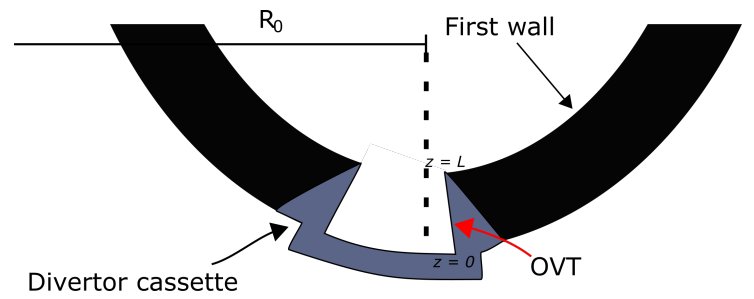

Figure 13: A basic sketch of the bottom section of tokamak showing the approximate divertor and OVT locations within the vacuum vessel. OxDTFC specific coordinates, with $z=0$ corresponding to the base of the OVT, are also marked.

The values of $\dot{q}_{p}$ and $\dot{q}_{B G}$ are determined by calculating the circumferential distribution of the power along the OVT via the geometric parameters of the tokamak:

$$
\bar{P}=\frac{\dot{P}_{\mathrm{OVT}}}{2 \pi R_{0}}
$$

where $R_{0}$ is the major radius of the vacuum vessel and is equal to $9.1 \mathrm{~m}$ in the DEMO1 tokamak [39]. This assumes that the OVT is approximately located as shown in Figure 13 .

Assuming an OVT poloidal length of $1 \mathrm{~m}$, and a peak heat flux of $10 \mathrm{MW} / \mathrm{m}^{2}$ halfway along the plate, yields the heat flux distribution shown in Figure 14.

\subsection{Comparison parameters}

The analysis compares single discrete, poloidally-oriented cooling sections of an OVT - performance results were calculated for one ITER-like monoblock cooling channel (Figure 2) and one array of HPJC-1a modules (Figure 11).

The total length of the each system in this comparison was set to $0.7 \mathrm{~m}$. This length corresponds to a total of 41 HPJC-1a modules.

The heat flux profile provided by Equation 34, with the strike point fixed at the midpoint of the strip $(0.35 \mathrm{~m}$ from the base), was used as the thermal boundary condition.

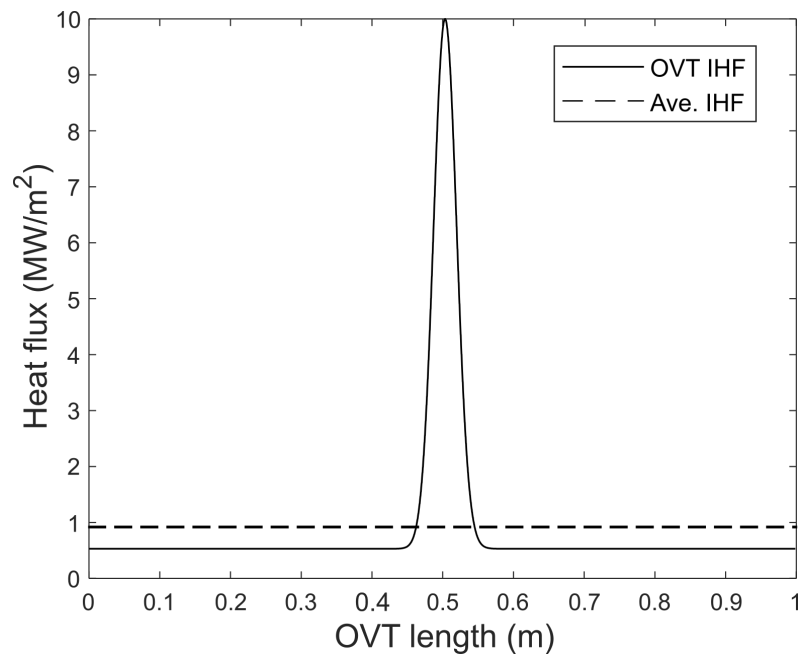

Figure 14: Derived heat flux profile incident on the OVT used in the divertor cooling system comparison, where $z=0$ is the bottom of the plate.

A maximum $\mathrm{CuCrZr}$ heat sink temperature $T_{h s, \max }$ of $300^{\circ} \mathrm{C}$ was set as the limiting thermal condition for each system. A peaking factor of 2 [12] was assumed when calculating the wall temperature of the ITER-like monoblock. To ensure fairness in conduction path length during the comparison the heat sink thickness was set to $1 \mathrm{~mm}$ for each system.

The geometric parameters of each system, noted in Figures 4 and 12, were set to:

- Toroidal Monoblock width: $20 \mathrm{~mm}$;

- Channel inner diameter: $12 \mathrm{~mm}$;

- Swirl tape thickness: $0.8 \mathrm{~mm}$;

- Swirl tape twist ratio: 2;

- HPJC-1a side length: $9.7 \mathrm{~mm}$.

Coolant inlet properties for the comparison were:

1. Inlet temperature: $150^{\circ} \mathrm{C}$

2. Inlet pressure: $5 \mathrm{MPa}$ (Monoblock), $15 \mathrm{MPa}$ (HPJC1a)

OxDTFC was used to calculate the required coolant flow rates for each system under these conditions. The resultant coolant flow rates are $1.5 \mathrm{~kg} / \mathrm{s}$ and $0.013 \mathrm{~kg} / \mathrm{s}$ for the ITER-like monoblock and a single HPJC-1a module, respectively.

For simplicity, and to provide a baseline PFC cooling system comparison, it was assumed each HPJC-1a module is connected in parallel and provided with the required flow rate - in actuality the manifold coolant distribution may differ from this case. Thus, the total coolant flow rate of the HPJC array is $0.53 \mathrm{~kg} / \mathrm{s}$, ensuring the HPJC 
Table 1: System comparison parameters.

\begin{tabular}{r|cc}
\hline Parameter & ITER-like Monoblock & HPJC-1a Array \\
\hline System length $[\mathrm{m}]$ & 0.7 & 0.7 \\
& Toroidal width $=20$ & \\
Key dimensions $[\mathrm{mm}]$ & $D_{i}=12$ & $s=9.7$ \\
& $\delta_{t}=0.8$ & \\
PFC area $\left[\mathrm{cm}^{2}\right]$ & $Y=2$ & 100 \\
Inlet temperature $\left[{ }^{\circ} \mathrm{C}\right]$ & 140 & 150 \\
Inlet pressure $[\mathrm{MPa}]$ & 150 & 15 \\
Coolant flow rate $[\mathrm{kg} / \mathrm{s}]$ & 5 & 0.013 (module)
\end{tabular}

system meets the specifications in the event of strike point sweeping.

The comparison parameters are summarized in Table 1.

\subsection{Results and discussion}

Figures 15 and 16 show the maximum heat sink temperature distributions along the OVT plate length under the conditions set out in the previous sections. The associated performance parameters of each system are given in Table 2 .

Manifold losses within the HPJC system are estimated as bulk pipe flow losses of the coolant traveling along the full length of both inlet and outlet coolant flow paths, equal to twice the length of the OVT in this comparison $(1.4 \mathrm{~m})$. Splitting and recombination losses are ignored as the fractional amount of coolant splitting and recombining at each module in the array is small [40]. To simplify the estimation, the inlet and outlet channels are assumed equivalent to a smooth pipe with a diameter of $10 \mathrm{~mm}$. Thus, total manifold losses are calculated by OxDTFC to be $\sim 0.5$ bar.

Along the OVT section of interest, the theoretical HPJC1a array has improved hydraulic performance relative to the ITER-like monoblock. Dividing these values by each system's plasma facing area, given in Table 1 , to create a normalized value to compare each system by, the required mass flow rate and associated pressure drop are shown to be $\sim 49 \%$ and $\sim 24 \%$ less, respectively, for the HPJC-1a array. This corresponds to a pumping power requirement for the HPJC-1a system that is $\sim 33 \%$ of the ITER-like monoblock system.

This large performance difference is due to the inherent efficiencies of the HPJC system. The use of jet impingement allows for much higher internal heat transfer coefficients for a given coolant flow rate, corresponding to less coolant needed for a given IHF. The cascading internal flow architecture also allows for the coolant flow rate to be decreased in exchange for a marginal increase in module pressure loss, compared to a similar module without cascading. To reach similar levels of heat transfer, the ITER-like monoblock must utilize more coolant at higher

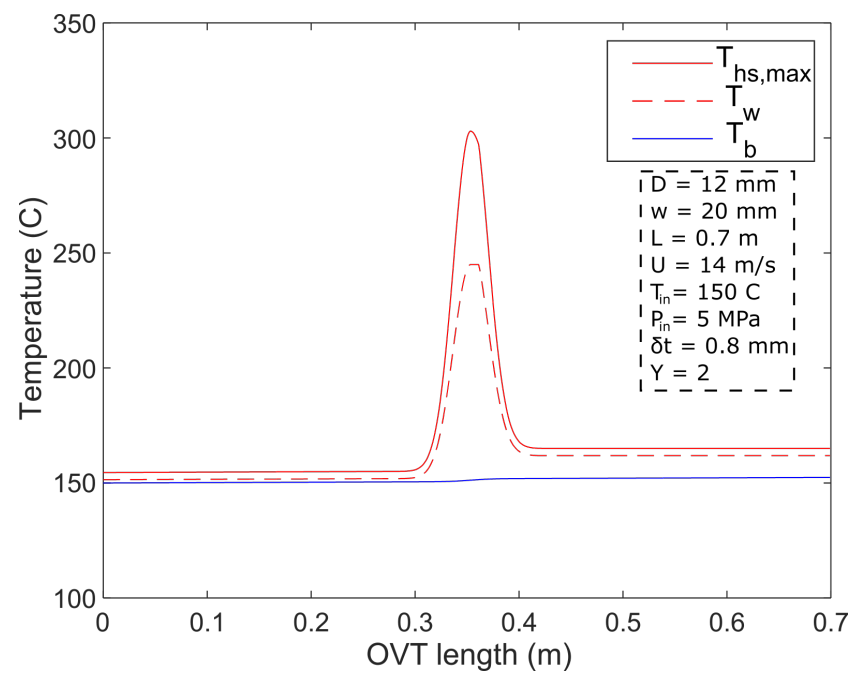

Figure 15: The maximum heat sink temperature, maximum wall temperature, and bulk coolant temperature plotted against the OVT length (origin at the base of the OVT, see Figure 13) for the ITERlike monoblock system analyzed in the comparison.

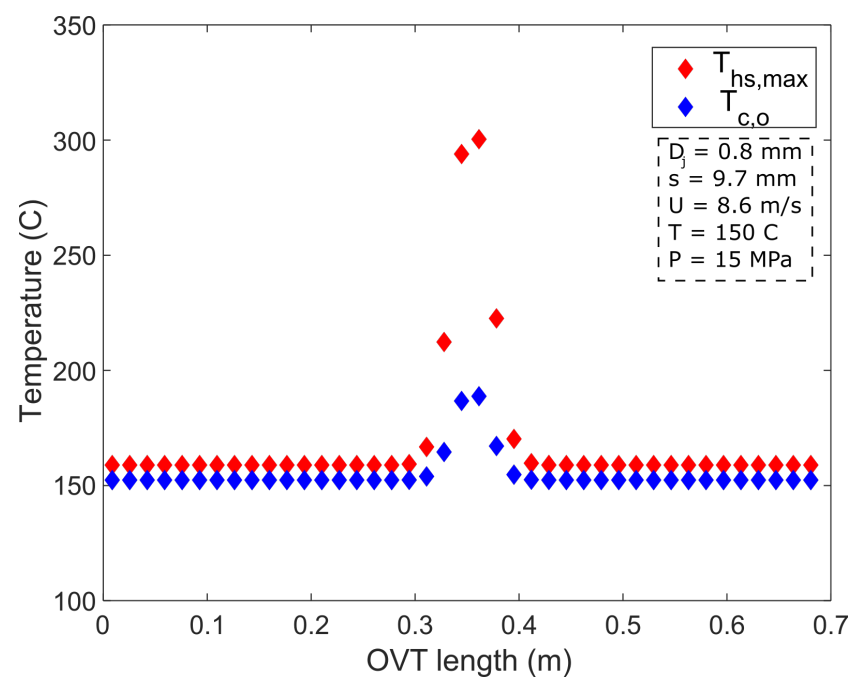

Figure 16: The maximum heat sink temperature and coolant exit temperature plotted against the OVT length (origin at the base of the OVT, see Figure 13) for the HPJC-1a modular system analyzed in the comparison. Each point corresponds to one module. 
Table 2: Performance characteristics of ITER-like monoblock and HPJC-1a modular array systems.

\begin{tabular}{l|cc}
\hline & ITER-like Monoblock & HPJC-1a \\
\hline Characteristic velocity $[\mathrm{m} / \mathrm{s}]$ & $14($ channel) & 9.4 (jet) \\
Coolant $\Delta \mathrm{T}\left[{ }^{\circ} \mathrm{C}\right]$ & 2.4 & $2.4-39$ \\
Mass flow rate $[\mathrm{kg} / \mathrm{s}]$ & 1.5 & 0.53 \\
Per PFC area $\left[\mathrm{kg} / \mathrm{m}^{2} \cdot \mathrm{s}\right]$ & 104 & 53 \\
Pressure drop $[\mathrm{MPa}]$ & 0.30 & 0.19 \\
Per PFC area $\left[\mathrm{MPa} / \mathrm{m}^{2}\right]$ & 21 & 16 \\
Pumping power $[\mathrm{W}]$ & 470 & 112 \\
Per PFC area $\left[\mathrm{kW} / \mathrm{m}^{2}\right]$ & 34 & 11
\end{tabular}

velocities, thereby leading to larger losses and high pumping power requirements.

This has a subsequent effect on the temperature pickup of each system. The low flow rates associated with the HPCJ-1a modules allow for much greater coolant temperature change, corresponding to a maximum of $39{ }^{\circ} \mathrm{C}$ in the region of peak heat flux and $2.4{ }^{\circ} \mathrm{C}$ outside of it. The ITER-like monoblock in contrast only gains $2.4{ }^{\circ} \mathrm{C}$ along the entire poloidal length.

These results are an initial indication of the HPJC module's potential benefits, and are not an exhaustive comparison. Further work needs to be done on how most efficiently to deploy and manifold the modular array. For example, by placing the modules exclusively in the region around the strike point, the full potential of the modules could be realized without wasting their capabilities in areas with low heat transfer demands. This could simplify the array manifold structure and potentially lead to further reductions in required coolant flow rates and pumping power. OxDTFC would be well suited to this task, where scripts could easily be developed and integrated to address this and other potential routes of module target plate optimization.

\section{Conclusion}

A one-dimensional rapid simulation numerical model, OxDTFC, has been developed to model the thermo-hydraulic performance of cooling systems in the vertical target plate region of the divertor in a tokamak fusion reactor. Two separate system models were developed within the code representing both the ITER-like monoblock and HPJC modular cooling systems. The HPJC model was developed specifically for the HPJC-1a design iteration, and was built using data gathered from experiments and computational fluid dynamics simulations done at the University of Oxford. The ITER-like monoblock model was validated against experimental data gathered by Boyd et al, Marshall et al, General Atomics, and CEA Cadarache. Very good agreement was found between OxDTFC over a range of incident heat fluxes, coolant flow rates, and swirl tape thicknesses and twist ratios.

OxDTFC was used to compare the performance of both systems under the same locally-varying, $10 \mathrm{MW} / \mathrm{m}^{2}$ peak heat flux profile and at similar coolant inlet conditions. OxDTFC demonstrated that, in a per-PFC area basis, the HPJC modular system outperforms the ITER-like monoblock in a few key metrics: pressure drop, pumping power, and coolant temperature change. In fact, the results showed that the HPJC-1a modular system would require $\sim 65 \%$ less pumping power while requiring $\sim 50 \%$ less coolant.

\section{Acknowledgements}

The authors gratefully recognise the support of the University of Oxford during the duration of this research. This work has been carried out within the framework of the EUROfusion Consortium and has received funding from the Euratom research and training programme 2014-2018 under grant agreement No 633053. The views and opinions expressed herein do not necessarily reflect those of the European Commission.

\section{References}

[1] The Divertor. 2018. URL: https : / / www . iter . org / mach / Divertor (visited on 06/10/2018).

[2] J Wesson. Tokamaks. Oxford University Press, 1997.

[3] C. B. Baxi. "Thermal hydraulics of water cooled divertors". In: Fusion Engineering and Design 56-57 (2001), pp. 195-198. ISSN: 09203796. DOI: 10.1016/S0920-3796(01) 00258-7.

[4] D. Maisonnier et al. "DEMO and fusion power plant conceptual studies in Europe". In: Fusion Engineering and Design 81.8-14 PART B (2006), pp. 1123-1130. ISSN: 09203796. DOI: $10.1016 / j$.fusengdes . 2005.08.055

[5] D. Maisonnier et al. "Power plant conceptual studies in Europe". In: Nuclear Fusion 47.11 (2007), pp. 1524-1532. ISSN: 00295515. DOI: $10.1088 / 0029-5515 / 47 / 11 / 014$.

[6] M. Merola. Divertor qualification phase well on track. 2008. URL: https : / / www. iter . org/newsline/38/773 (visited on 06/24/2018)

[7] A. Li-Puma et al. "Potential and limits of water cooled divertor concepts based on monoblock design as possible candidates for a DEMO reactor". In: Fusion Engineering and Design 88.910 (2013), pp. 1836-1843. ISSN: 09203796. DOI: $10.1016 / \mathrm{j}$. fusengdes.2013.05.114. URL: http://dx.doi.org/10.1016/ j.fusengdes. 2013.05.114.

[8] P. Norajitra. "Divertor Development for a Future Fusion Power Plant". PhD thesis. Karlsruher Institut fur Technologie, 2011. ISBN: 978-3-86644-738-7. 
[9] P. Norajitra et al. "European development of He-cooled divertors for fusion power plants". In: Nuclear Fusion 45.11 (2005), pp. 1271-1276. ISSN: 17414326. DOI: $10.1088 / 0029-5515 / 45 /$ $11 / 007$.

[10] J. R. Nicholas et al. "Development of a heat sink module for a near-term DEMO divertor". In: Fusion Engineering and Design 133.May (2018), pp. 77-88. ISSN: 09203796. DOI: 10.1016/ j.fusengdes .2018.05.070. URL: https://doi.org/10.1016/ j.fusengdes. 2018.05.070.

[11] R. A. Pitts et al. "Physics conclusions in support of ITER W divertor monoblock shaping". In: Nuclear Materials and Energy 12 (2017), pp. 60-74. ISSN: 23521791. DOI: $10.1016 / \mathrm{j}$. nme. 2017.03 .005

[12] J. H. You et al. "Conceptual design studies for the European DEMO divertor: Rationale and first results". In: Fusion Engineering and Design 109-111.PartB (2016), pp. 1598-1603. ISSN: 09203796. DOI: 10.1016/j.fusengdes.2015.11.012.

[13] T. Barrett et al. "Progress in the Engineering Design and Assessment of the European DEMO First Wall and Divertor Plasma Facing Components Presentation overview". In: September (2015).

[14] Jeong Ha You. "A review on two previous divertor target concepts for DEMO: Mutual impact between structural design requirements and materials performance". In: Nuclear Fusion 55.11 (2015). ISSN: 17414326. DOI: 10.1088/0029-5515/55/11/ 113026.

[15] S. E. D. El-Morshedy and A. Hassanein. "Transient thermal hydraulic modeling and analysis of ITER divertor plate system". In: Fusion Engineering and Design 84.12 (2009), pp. 2158 2166. ISSN: 09203796. DOI: $10.1016 /$ j.fusengdes . 2009 . 02 . 051.

[16] P. A. Di Maio et al. "On the thermal-hydraulic optimization of DEMO divertor plasma facing components cooling circuit". In: Fusion Engineering and Design 136.September 2017 (2018), pp. 1438-1443. ISSN: 09203796. DOI: $10.1016 / \mathrm{j}$.fusengdes . 2018.05.032. URL: https://doi.org/10.1016/j.fusengdes . 2018.05 .032 .

[17] P. A. Di Maio et al. "Hydraulic analysis of EU-DEMO divertor plasma facing components cooling circuit under nominal operating scenarios". In: Fusion Engineering and Design January (2019), pp. -1. ISSN: 09203796. DOI: $10.1016 / \mathrm{j}$. fusengdes . 2019.03.030. URL: https://doi.org/10.1016/j.fusengdes . 2019.03 .030$.

[18] E. W. Lemmon, M. L. Huber, and M. O. McLinden. "NIST Standard Reference Database 23: Reference Fluid Thermodynamic and Transport Properties-REFPROP, Version 9.1". In: National Institutes of Standards and Technology (2017).

[19] "Appendix A, Materials Design Limit Data". In: ITER Structural Criterion for in fffdfffdffd vessel components (SDC-IC) (2013).

[20] Y. Çengel. Heat and Mass Transfer, A Practical Approach. 3rd Ed. McGraw-Hill, 20006. ISBN: 007125739X.

[21] C. B. Baxi. "Comparison of Swirl Tube and Hypervapotron for Cooling of ITER Divertor". In: Proceedings of 16th International Symposium on Fusion Engineering (1995), pp. 186189.

[22] J. H. You et al. "Progress in the initial design activities for the European DEMO divertor: Subproject fffdfffdfffdCassettefffdfffdfffd". In: Fusion Engineering and Design 124 (2017), pp. 364-370. ISSN: 09203796. DOI: 10.1016/j.fusengdes. 2017. 03.018. URL: https://doi.org/10.1016/j.fusengdes . 2017. 03.018.
[23] J Boscary. "Dimensional analysis of critical heat flux in subcooled water flow under one-side heating conditions for fusion application". In: Fusion Engineering and Design 43.2 (1998), pp. 147-171. ISSN: 09203796. DOI: 10.1016/s0920-3796(98) 00387-1. URL: http://linkinghub.elsevier.com/retrieve/ pii/S0920379698003871.

[24] R. D. Boyd. A final report from the Thermal Science Research Center (TSRC). Tech. rep. Thermal Science Research Center, Roy G. Perry College of Engineering, Prarie View A\&M University, 2014.

[25] F. W. Dittus and Boelter. Publications on Engineering. University of California, Berkeley, 1930.

[26] E.N. Sieder and G.E. Tate. "Heat transfer and pressure drop of liquids in tubes". In: Industrial and Engineering Chemistry 28 (1936), pp. 1429-1435.

[27] W.R. Gambill, R.D. Bundy, and R.W. Wansbrough. "Heat transfer, burnout, and pressure drop for water in swirl flow tubes with internal twisted tapes". In: Chem. Eng. Prog. Symp. Ser. 57.32 (1961), pp. 127-137.

[28] J.G. Collier and J. R. Thome. Convective Boiling and Condensation. 3rd Ed. Oxford: Oxford University Press, 1994.

[29] J.C. Chen. "A correlation for boiling heat transfer to saturated fluids in convective flow". In: Industrial and Engineering Chemistry, Process Design and Development 5.3 (1966), pp. 322-329.

[30] H. Steiner, A. Kobor, and L. Gebhard. "A wall heat transfer model for subcooled boiling flow". In: International Journal of Heat and Mass Transfer 48.19-20 (2005), pp. 4161-4173. ISSN: 00179310. DOI: $10.1016 / \mathrm{j}$. i jheatmasstransfer.2005.03.032.

[31] N. I. Kolev. Multiphase Flow Dynamics 2: Thermal and Mechanical Interactions. 3rd Ed. Berlin: Springer, 2007. ISBN: 978-3-540-69834-0.

[32] R. F. Lopina and A. E. Bergles. "Heat Transfer and Pressure Drop in Tape Generated Swirl Flow". In: (1967).

[33] R. D. Boyd et al. "Multidimensional heat transfer and flow boiling curve measurements in single-side-heated flow channels". In: Fusion Science and Technology 70.3 (2016), pp. 448460. ISSN: 15361055. DOI: 10.13182/FST16-102.

[34] T.D. Marshall, D.L. Youchinson, and L.C Cadwallader. "Modeling the Nukiyama curve for water-cooled fusion divertor channels". In: Fusion Technology 39 (2001).

[35] T.D. Marshall. "FILM-30 : A Heat Transfer Properties Code for Water Coolant". In: Sandia Report (2001).

[36] A R Raffray et al. Critical heat flux analysis and $R$ \& $D$ for the design of the ITER divertor. Vol. 45. 1999, pp. 377-407. ISBN: 8585347716 .

[37] R. P. Wenninger et al. "DEMO divertor limitations during and in between ELMs". In: Nuclear Fusion 54.11 (2014). ISSN: 17414326. DOI: 10.1088/0029-5515/54/11/114003.

[38] T. Eich et al. "Scaling of the tokamak near the scrape-off layer H-mode power width and implications for ITER". In: Nuclear Fusion 53.9 (2013). ISSN: 00295515. DOI: 10.1088/0029-5515/ $53 / 9 / 093031$.

[39] G. Federici et al. "European DEMO design strategy and consequences for materials". In: Nuclear Fusion 57.9 (2017). ISSN: 17414326. DOI: $10.1088 / 1741-4326 / 57 / 9 / 092002$.

[40] D. S. Miller. Internal Flow Systems. 2nd Ed. Cranfield, Bedford: BHRA (Information Services), 1990. ISBN: 0-947711-77-5. 


\section{Appendix A. Flowcharts}

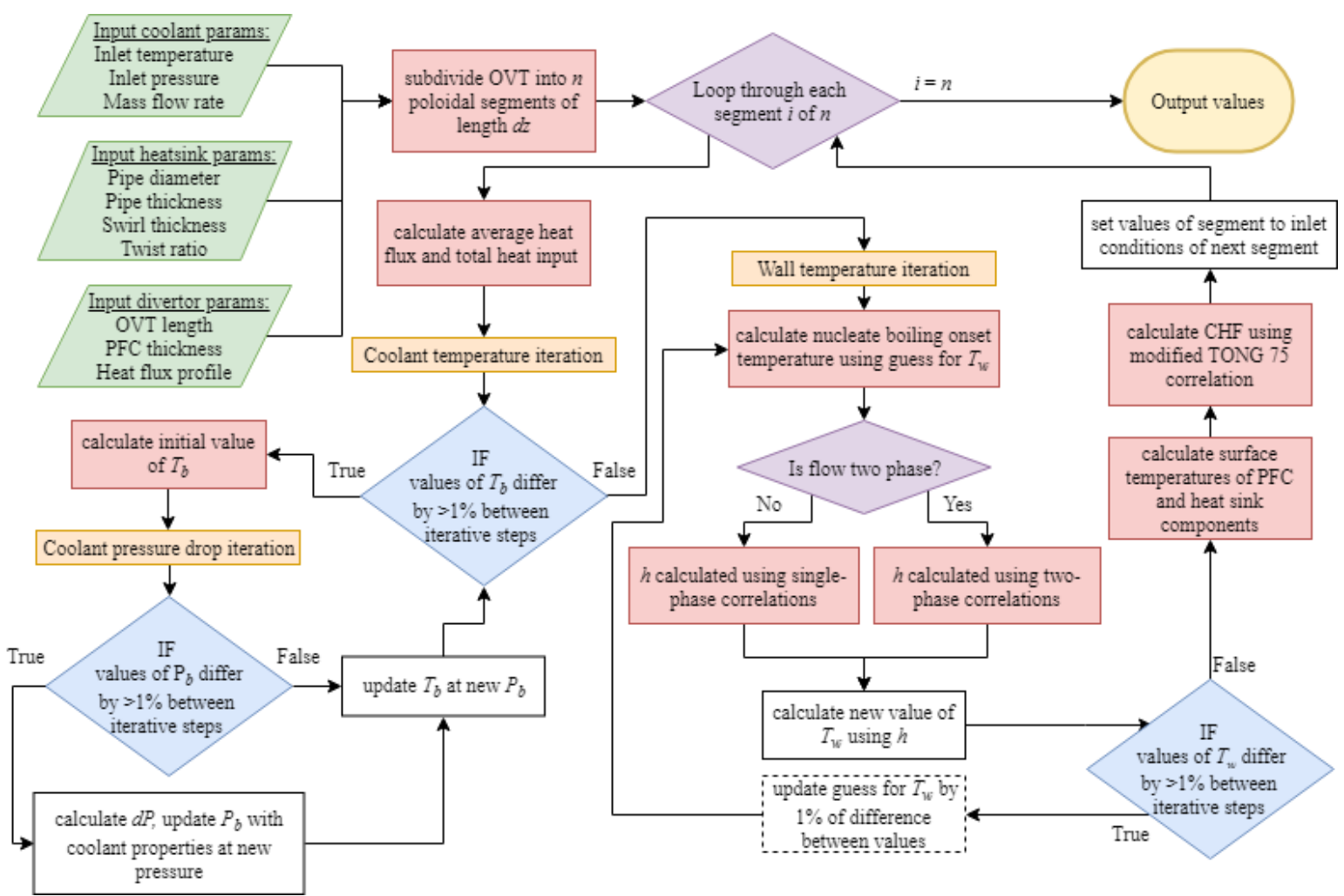

Figure A.17: ITER-like monoblock code flowchart.

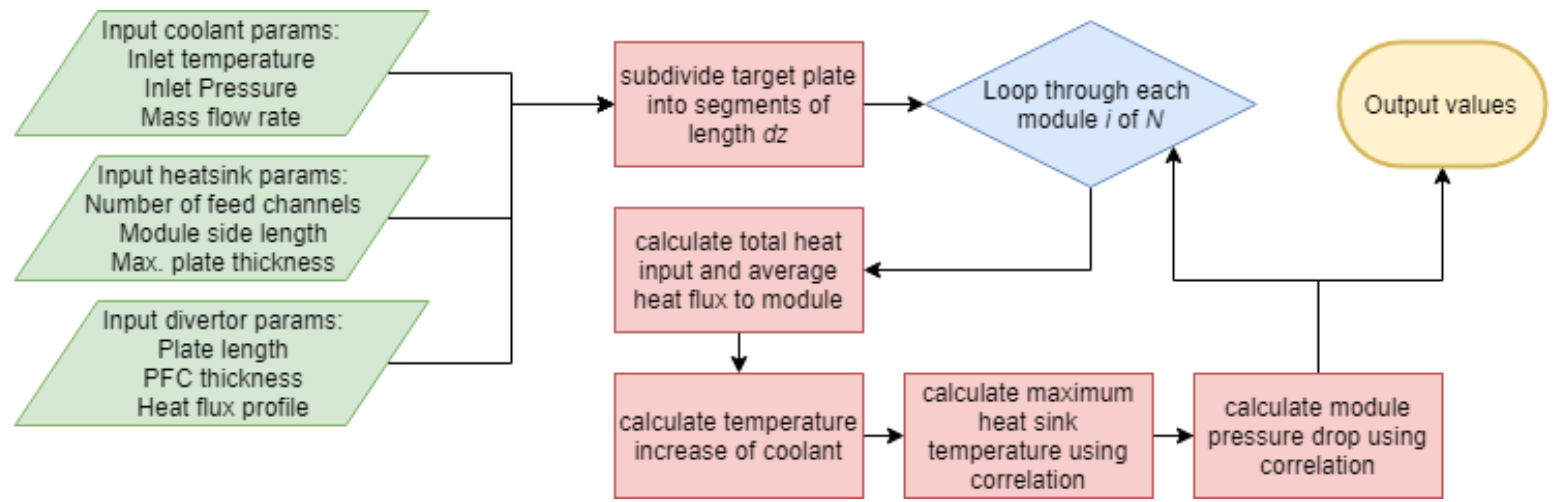

Figure A.18: HPJC code flowchart. 